\title{
A multicopy suppressor screening approach as a means to identify antibiotic resistance determinant candidates in Yersinia pestis Karen L Stirrett ${ }^{1}$, Julian A Ferreras ${ }^{1}$, Sebastian M Rossi1,2, Richard L Moy1, Fabio V Fonseca ${ }^{1,3}$ and Luis EN Quadri*1
}

Address: ${ }^{1}$ Department of Microbiology and Immunology, Weill Medical College of Cornell University, 1300 York Avenue, New York, New York 10021, USA, ${ }^{2}$ Universidad Nacional de Misiones, Facultad de Ciencias Exactas, Quimicas y Naturales, Felix de Azara 1552, C.P. N3300LQH, Posadas, Argentina and ${ }^{3}$ Medical College of Georgia, Vascular Biology Center, 1459 Laney Walker Boulevard, CB 3201B, Augusta, Georgia 30912, USA

Email: Karen L Stirrett - kls2002@med.cornell.edu; Julian A Ferreras - juf2003@med.cornell.edu; Sebastian M Rossi - maximiliano000@hotmail.com; Richard L Moy - rlm4100@yahoo.com; Fabio V Fonseca - ffonseca@mail.mcg.edu; Luis EN Quadri* - leq2001@med.cornell.edu

* Corresponding author

Published: 21 July 2008

BMC Microbiology 2008, 8:122 doi:10.1186/147|-2180-8-122

Received: 29 April 2008

Accepted: 21 July 2008

This article is available from: http://www.biomedcentral.com/I47I-2I80/8/I22

(C) 2008 Stirrett et al; licensee BioMed Central Ltd.

This is an Open Access article distributed under the terms of the Creative Commons Attribution License (http://creativecommons.org/licenses/by/2.0), which permits unrestricted use, distribution, and reproduction in any medium, provided the original work is properly cited.

\begin{abstract}
Background: Yersinia pestis is the causative agent of plague and a potential agent of bioterrorism and biowarfare. The plague biothreat and the emergence of multidrug-resistant plague underscore the need to increase our understanding of the intrinsic potential of $Y$. pestis for developing antimicrobial resistance and to anticipate the mechanisms of resistance that may emerge in $Y$. pestis. Identification of $Y$. pestis genes that, when overexpressed, are capable of reducing antibiotic susceptibility is a useful strategy to expose genes that this pathogen may rely upon to evolve antibiotic resistance via a vertical modality. In this study, we explored the use of a multicopy suppressor, Escherichia coli host-based screening approach as a means to expose antibiotic resistance determinant candidates in $Y$. pestis.
\end{abstract}

Results: We constructed a multicopy plasmid-based, $Y$. pestis genome-wide expression library of nearly 16,000 clones in $E$. coli and screened the library for suppressors of the antimicrobial activity of ofloxacin, a fluoroquinolone antibiotic. The screen permitted the identification of a transcriptional regulator-encoding gene $\left(r o b A_{Y_{p}}\right)$ that increased the $\mathrm{MIC}_{99}$ of ofloxacin by 23 -fold when overexpressed from a multicopy plasmid in $Y$. pestis. Additionally, we found that robA $A_{Y p}$ overexpression in $Y$. pestis conferred low-level resistance to many other antibiotics and increased organic solvent tolerance. Overexpression of $r_{0 b} A_{Y_{P}}$ also upregulated the expression of several efflux pumps in $Y$. pestis.

Conclusion: Our study provides proof of principle for the use of multicopy suppressor screening based on the tractable and easy-to-manipulate $E$. coli host as a means to identify antibiotic resistance determinant candidates of $Y$. pestis. 


\section{Background}

Yersinia pestis $(Y p)$ is one of the most virulent known bacteria [1] and a potential agent of bioterrorism and biowarfare $[2,3]$ included in the Category A of biological agents for public health preparedness against bioterrorism [4]. $Y p$ is the etiologic agent of plague, a disease responsible for millions of human deaths during the history of civilization $[5,6]$. Cases are reported every year in many parts of the world [7] and the increasing number of worldwide cases has placed plague in the category of re-emerging diseases [8].

Patients with plague need prompt antibiotic treatment or else death may be unavoidable. The aminoglycosides streptomycin (STR) and gentamicin (GEN) are the preferred antibiotics for treatment, but a number of other drugs are also effective $[9,10]$. Tetracyclines [such as doxycycline (DOX)], chloramphenicol (CHL), or selected sulfonamides are the recommended antibiotics for prophylactic therapy in the event of exposure or high risk of exposure to $Y p[2,9,10]$. Fluoroquinolones have also been suggested for treatment and prophylaxis and are noted as a chemotherapeutic alternative against strains resistant to the first line anti-plague drugs $[2,10]$.

The threat of bioterrorism-generated plague outbreaks with engineered (multi)drug-resistant $Y p$ strains [2,3] and the documented outbreak of multidrug-resistant plague [11] underscore the need to develop alternative chemotherapeutic solutions to this disease. In line with this view, we are exploring the development of anti-infectives that target the high-affinity iron acquisition system of $Y p[12-$ 14] and may offer novel therapeutic possibilities [15]. The plague biothreat also underscores the need to increase our understanding of the intrinsic potential of $Y p$ for developing antimicrobial resistance and to anticipate the mechanisms of resistance that may emerge in Yp clinical isolates in the future. With this consideration in mind, we explored herein the use of a multicopy suppressor screening approach as a means to expose antibiotic resistance determinant candidates in $Y p$. Multicopy suppressor screening has been useful to study potential drug targets or mechanisms of antibiotic resistance in other species [16]. We constructed a multicopy plasmid-based, Yp genome-wide expression library of nearly 15,000 clones in $E$. coli $(E c)$, a tractable and easy-to-manipulate surrogate bacterial host, and screened the library for suppressors of the antimicrobial activity of the fluoroquinolone antibiotic ofloxacin (OFX). Noteworthy, fluoroquinolones have been suggested by the Working Group on Civilian Biodefense as alternative drugs in the event of the use of aerosolized $Y p$ as a bioweapon against a civilian population [2]. The screen permitted the identification of a gene that reduced the susceptibility of $Y p$ to fluoroquinolones and other antibiotic classes when overexpressed from a multicopy plasmid. Our study provides proof of principle for the utilization of multicopy suppressor screening using an $E c$ host as a means to identify antibiotic resistance determinant candidates in $Y p$.

\section{Results and Discussion}

A multicopy suppressor screen led to the isolation of a $\mathrm{Y}$. pestis genomic fragment involved in ofloxacin resistance

We constructed a plasmid-based expression library of the $Y p$ genome comprised of 15,648 Ec clones and screened the library for strains with reduced OFX susceptibility. A strain (Ec pGEM-OFXr1) selected in the screen exhibiting reduced susceptibility that was confirmed to be plasmidmediated and transferable to $Y p$ was chosen for further characterization (Figure 1). The plasmid (pGEM-OFXr1) carried by this strain was isolated and the restriction digestion pattern and sequence of its genomic insert were examined. This analysis revealed a 4,158-bp fragment ( $Y p$ KIM chromosome coordinates $4,137,482$ to $4,141,639$ ) (Figure 2). The 5' and 3' ends of the fragment included the $5^{\prime}$ end of $y 3722(\mathrm{creA})$ and the 3 ' end of $y 3727$ (slt), respectively. The products of creA and slt are annotated as a conserved hypothetical protein and a putative soluble lytic murein transglycosylase, respectively, in the $Y p$ genome database. The center of the fragment encompassed four genes: $y 3723$ (robA, herein referred to as $r o b A_{\mathrm{Yp}}$ ); $\gamma 3724$ $(g p m B) ; \gamma 3725 ;$ and $\gamma 3726$ (trpR). The products of gpmB and $\operatorname{trpR}$ are annotated as a putative phosphoglyceromutase and a putative regulator of tryptophan metabolism genes, respectively. The product of y3725 is annotated as a conserved hypothetical protein. Our in silico search for conserved domains (via CD-Search; please see Availability \& requirements for more details) revealed the presence of an NTPase (PRK05074) domain in this protein. The NTPase domain is characteristic of proteins with pyrophosphatase activity $[17,18]$. This suggested that y3725 may be involved in nucleoside triphosphate metabolism. Lastly, the predicted product of $r o b A_{Y p}\left(R_{0 b A_{Y P}}\right)$ is annotated as an orthologue of $E c$ RobA ( $\left(\operatorname{RobA}_{\mathrm{Ec}}\right)$, a transcriptional regulator of unclear physiological function and member of the AraC/XylS family [19]. Importantly, overexpression of rob $A_{\mathrm{Ec}}$ and Enterobacter cloacae robA confers low-level resistance in $E c$ and E. cloacae, respectively, to a number of unrelated antibiotics [20-22]. Thus, the analysis of the insert in pGEM-OFXr1 suggested that $r o b A_{Y p}$ is responsible for the reduced OFX susceptibility observed in Ec pGEM-OFXr1 and $Y p$ pGEM-OFXr1 (Figure 1 ). These results validate the utility of our library and suppressor screen approach as a means to identify antibiotic resistance determinant candidates in $Y p$.

\section{Overexpression of robA ${ }_{Y p}$ affects susceptibility to multiple antibiotics}

We investigated whether overexpression of rob $A_{\mathrm{Yp}}$ alone would reduce OFX susceptibility in $E c$ and, more impor- 

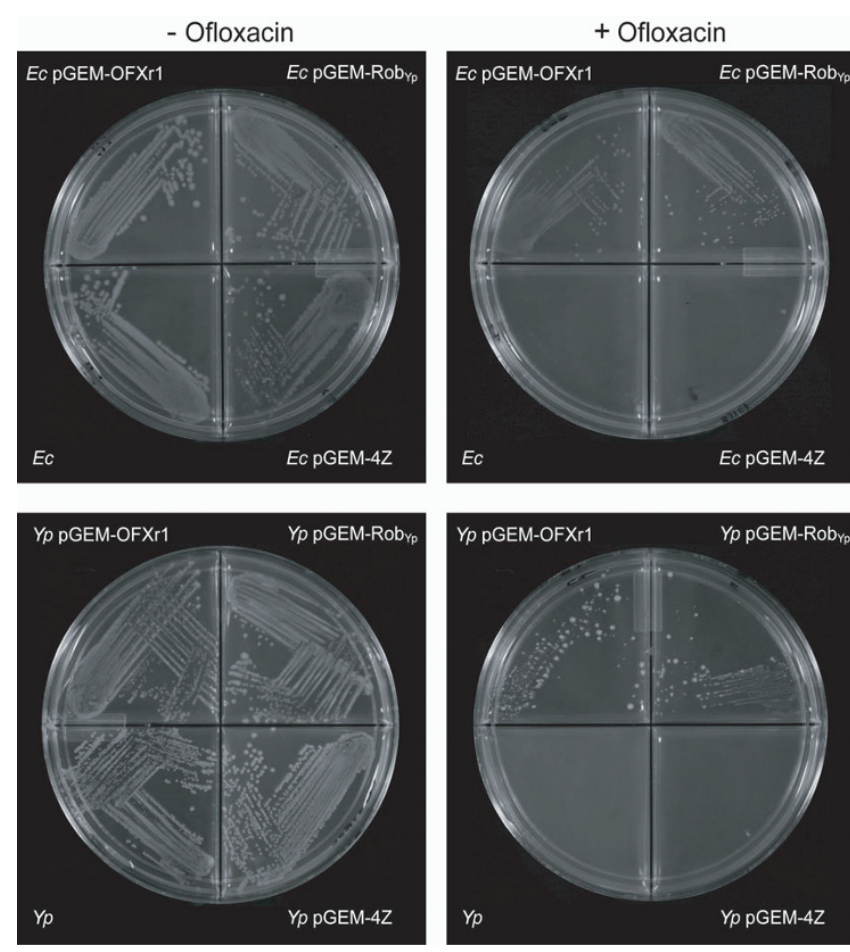

Figure I

Reduction of ofloxacin susceptibility conferred by plasmids pGEM-OFXrI and pGEM-Rob $\mathbf{Y p}_{\mathbf{p}}$. E. coli (EC) and $Y$. pestis $(Y p)$ strains were streaked on solid media without or with ofloxacin: $0.35 \mu \mathrm{g} / \mathrm{ml}$ (the concentration used in the screen) for $E$. coli and $0.15 \mu \mathrm{g} / \mathrm{ml}$ for $Y$. pestis. Ampicillin $(\mathrm{I} 00 \mu \mathrm{g} / \mathrm{ml})$ was also added to the media for plasmid-carrying strains.

tantly, in $Y p$. To this end, we evaluated the antibiotic susceptibility of Ec pGEM-Rob ${ }_{\mathrm{Yp}}$ and Yp pGEM-Rob $\mathrm{p}_{\mathrm{Yp}}$. These test strains carried $\mathrm{pGEM}-\mathrm{Rob}_{\mathrm{Yp}^{\prime}}$ a plasmid constructed by inserting the fragment encompassing $r o b A_{\mathrm{Yp}}$ and its promoter region (identified by using the rob $A_{\mathrm{Ec}}$ promoter as reference [23]) into the vector pGEM-4Z. The antibiotic susceptibilities of these test strains were compared to that of the corresponding Ec pGEM-4Z and Yp pGEM-4Z con- trol strains. These control and test strains were isogenic, except for the lack of the plasmid-borne $\operatorname{rob} A_{\mathrm{Yp}^{\prime}}$ and their growth in ampicillin (AMP)-containing liquid media was indistinguishable from that of their cognate test strains (not shown). A first examination of Ec pGEM-Rob p $_{\mathrm{Yp}}$ and $Y p$ pGEM-Rob $\mathrm{Yp}_{\mathrm{Y}}$ indicated that these strains retained the reduced OFX susceptibility phenotype seen in Ec pGEMOFXr1 and Yp pGEM-OFXr1 on solid media (Figure 1), thus indicating that $r o b A_{Y p}$ alone was sufficient to reduce OFX susceptibility. In view of this, we conducted further OFX susceptibility testing in liquid media. In addition, we compared the susceptibility of the test and control strains to two other fluoroquinolones [ciprofloxacin (CIP) and levofloxacin (LVX)], a quinolone (NAL), and antibiotics of other classes, including two tetracyclines [tetracycline (TET) and DOX], four aminoglycosides [STR, GEN, kanamycin (KAN), and apramycin (APR)], and CHL.

The $\mathrm{IC}_{50}$ and $\mathrm{MIC}_{99}$ values determined for the aforementioned antibiotics are shown in Table 1. Comparison of the OFX $\mathrm{IC}_{50}$ and OFX $\mathrm{MIC}_{99}$ values of the test strains and their respective control strains revealed that overexpression of robA $A_{\mathrm{Yp}}$ reduced OFX susceptibility in both $Y p$ and $E c$. In $Y p$, rob $A_{Y p}$ overexpression increased OFX $\mathrm{IC}_{50}$ and $\mathrm{OFX}_{\mathrm{MIC}_{99}}$ values by 5-fold and 23-fold, respectively. The $\mathrm{IC}_{50}$ and $\mathrm{MIC}_{99}$ values of CIP, LVX, and NAL also increased significantly (3- to 5-fold change range) in Yp pGEMRob $_{Y p}$ compared with Yp pGEM-4Z. The reduced OFX and LVX susceptibility of Yp pGEM-Rob ${ }_{Y p}$ was also revealed by time-kill experiments described below. In $E c$, rob $A_{\mathrm{Yp}}$ overexpression produced an increase in the $\mathrm{IC}_{50}$ and $\mathrm{MIC}_{99}$ of the fluoroquinolone antibiotics (2- to 4-fold change range), but had no significant effect ( $<2$-fold change) on NAL susceptibility.

In both $Y p$ and $E c$, rob $A_{\mathrm{Yp}}$ overexpression also correlated with an increase in the $\mathrm{IC}_{50}$ and $\mathrm{MIC}_{99}$ of the two tetracyclines tested and CHL (2- to 7 -fold change range). No substantial impact (<2-fold change) on the $\mathrm{MIC}_{99}$ values of four aminoglycosides tested was detected in $Y p$ upon overexpression of robA $A_{\mathrm{Yp}}$. Interestingly, however, the $\mathrm{IC}_{50}$ val-

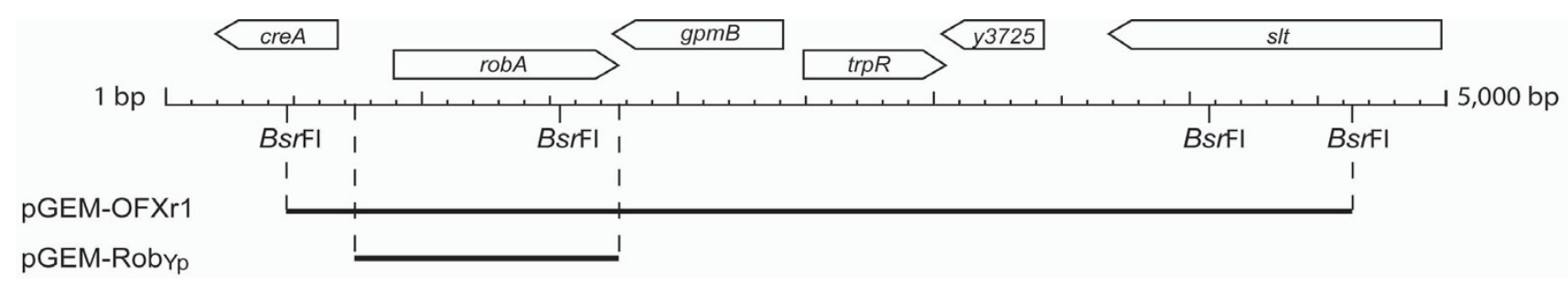

Figure 2

Genetic map of the robA ${ }_{Y p}$-containing region of the $Y$. pestis KIM chromosome and inserts of pGEM-OFXrI and PGEM-Rob ${ }_{Y \mathbf{p}}$. 
Table I: Effect of robA $A_{Y p}$ overexpression on antibiotic susceptibility

\begin{tabular}{|c|c|c|c|c|c|c|c|c|}
\hline \multirow[b]{2}{*}{ Y. pestis } & \multicolumn{3}{|c|}{$\mathrm{IC}_{50}(\mu \mathrm{g} / \mathrm{ml})^{\mathrm{a}}$} & \multirow[t]{2}{*}{$\mathrm{FCc}$} & \multicolumn{3}{|c|}{$\mathrm{MIC}_{99}(\mu \mathrm{g} / \mathrm{ml})^{\mathrm{b}}$} & \multirow[t]{2}{*}{$\mathrm{FC}$} \\
\hline & no plasmid & PGEM-4Z & PGEM-Rob ${ }_{Y p}$ & & no plasmid & pGEM-4Z & pGEM-Rob ${ }_{Y P}$ & \\
\hline Ofloxacin & 0.01 & 0.01 & 0.05 & 5 & 0.03 & 0.03 & 0.7 & 23 \\
\hline Ciprofloxacin & 0.009 & 0.009 & 0.04 & 4 & 0.02 & 0.02 & 0.09 & 5 \\
\hline Levofloxacin & 0.01 & 0.01 & 0.04 & 4 & 0.02 & 0.02 & 0.09 & 5 \\
\hline Nalidixic Acid & 0.5 & 0.8 & 2 & 3 & 2 & 2 & 6 & 3 \\
\hline Chloramphenicol & 0.3 & 0.4 & 0.9 & 2 & I & I & 3 & 3 \\
\hline Tetracycline & 0.7 & 1 & 6 & 6 & I & 3 & 10 & 3 \\
\hline Doxycycline & 0.4 & 0.5 & I & 2 & 0.6 & I & 3 & 3 \\
\hline Kanamycin & 1 & 0.9 & 0.4 & 0.4 & 2 & 2 & 2 & I \\
\hline Apramycin & 2 & 3 & 1 & 0.3 & 6 & 6 & 4 & 0.7 \\
\hline Streptomycin & 1 & 2 & 0.8 & 0.4 & 3 & 3 & 3 & I \\
\hline Gentamicin & 0.4 & 0.4 & 0.2 & 0.5 & 1 & 0.4 & 0.4 & I \\
\hline E. coli & no plasmid & PGEM-4Z & PGEM-Rob ${ }_{Y P}$ & & no plasmid & pGEM-4Z & pGEM-Rob $_{Y_{p}}$ & \\
\hline Ofloxacin & 0.03 & 0.04 & 0.09 & 2 & 0.08 & 0.2 & 0.4 & 2 \\
\hline Ciprofloxacin & 0.01 & 0.009 & 0.04 & 4 & 0.05 & 0.08 & 0.2 & 3 \\
\hline Levofloxacin & 0.04 & 0.04 & 0.1 & 3 & 0.2 & 0.2 & 0.4 & 2 \\
\hline Nalidixic Acid & 27 & 26 & 28 & 1 & 83 & 100 & 100 & I \\
\hline Chloramphenicol & 0.3 & 0.3 & 0.8 & 3 & 2 & 2 & 13 & 7 \\
\hline Tetracycline & 0.8 & 0.6 & 2 & 3 & 3 & 3 & 10 & 3 \\
\hline Doxycycline & 0.3 & 0.2 & 0.6 & 3 & 1 & 0.6 & 3 & 5 \\
\hline Kanamycin & 2 & 1 & 2 & 2 & 10 & 6 & 6 & I \\
\hline Apramycin & 3 & 3 & 4 & 1 & 21 & 17 & 21 & I \\
\hline Streptomycin & 3 & 2 & 3 & 2 & 17 & 13 & 13 & I \\
\hline Gentamicin & 0.9 & 0.6 & 2 & 3 & 6 & 5 & 8 & 2 \\
\hline
\end{tabular}

${ }^{a} I_{50}$ values were calculated from sigmoidal curves fitted to triplicate sets of dose-response data. ${ }^{b} \mathrm{MIC}_{99}$ values are means of triplicates. ${ }^{\mathrm{c}}$ Fold change (FC) values were calculated as the ratio of the $I_{50}$ or MIC $C_{99}$ of the pGEM-Rob ${ }_{Y p}$ transformants to the IC $C_{50}$ or MIC ${ }_{99}$ of the pGEM-4Z transformants. $I_{50}, M I C_{99}$, and $F C$ values $<I$ and values $>I$ were rounded to one significant digit and to the nearest non-fractional number, respectively.

ues of these aminoglycosides were reproducibly and consistently lower (2- to 3 -fold reduction range) in $Y p$ pGEM-Rob ${ }_{\mathrm{Yp}}$ compared with $Y p$ pGEM-4Z. These results indicated that $r o b A_{\mathrm{Yp}}$ overexpression increased the susceptibility of $Y p$ to aminoglycosides. The hypersensitivity of $Y p$ pGEM-Rob ${ }_{\mathrm{Yp}}$ to aminoglycosides was also observed in time-kill experiments described below. Aminoglycoside hypersensitivity was not observed in Ec pGEM-Rob ${ }_{\mathrm{Yp}}$. On the contrary, the strain had a modest decrease in the susceptibility to GEN, STR, and KAN (2- to 3-fold change range) relative to $E c$ pGEM- $4 Z$.

Overall, the phenotypic comparison of the antibiotic susceptibility of pGEM-Rob ${ }_{\mathrm{Yp}}$-bearing strains and pGEM-4Zbearing strains clearly demonstrates that $r o b A_{\mathrm{YP}}$ overexpression affects antibiotic susceptibility in both $Y p$ and $E c$, yet in a noticeably species-specific manner. As discussed below, the effects on antibiotic susceptibility induced by $r o b A_{Y \mathrm{Y}}$ overexpression are likely due to an upregulation of efflux pumps. Thus, the species-specific differences in antibiotic susceptibility are probably produced by speciesspecific differences in efflux pump upregulation.
Overexpression of robA $\mathrm{Y}_{\mathrm{p}}$ in $\mathrm{Y}$. pestis reduces killing by fluoroquinolones but enhances killing by aminoglycosides The comparative analysis of $\mathrm{IC}_{50}$ and $\mathrm{MIC}_{99}$ values described above indicated that $Y p$ pGEM-Rob $b_{Y p}$ has reduced fluoroquinolone susceptibility and increased aminoglycoside susceptibility compared with Yp pGEM$4 Z$. To further probe these phenotypes, we examined the killing kinetics of these two strains when exposed to OFX, CIP, STR, and GEN (Figure 3). The profiles of the time-kill curves for OFX and CIP demonstrated that the Yp pGEM$4 \mathrm{Z}$ control was more rapidly killed by the fluoroquinolones than $Y p$ pGEM-Rob ${ }_{\mathrm{Yp}}$. Conversely, the profiles of the time-kill curves for STR and GEN revealed that Yp pGEMRob $_{\mathrm{Yp}}$ was more rapidly killed by the aminoglycosides than the Yp pGEM-4Z control. Both strains had comparable growth in the absence of fluoroquinolone or aminoglycoside antibiotics during the time frame of the time-kill assays. The contrasting effects of $r o b A_{Y p}$ overexpression on fluoroquinolone- and aminoglycoside-mediated killing are consistent with the results of the comparative analysis of $\mathrm{IC}_{50}$ and $\mathrm{MIC}_{99}$ values (Table 1). The observed aminoglycoside hypersensitivity is some- 

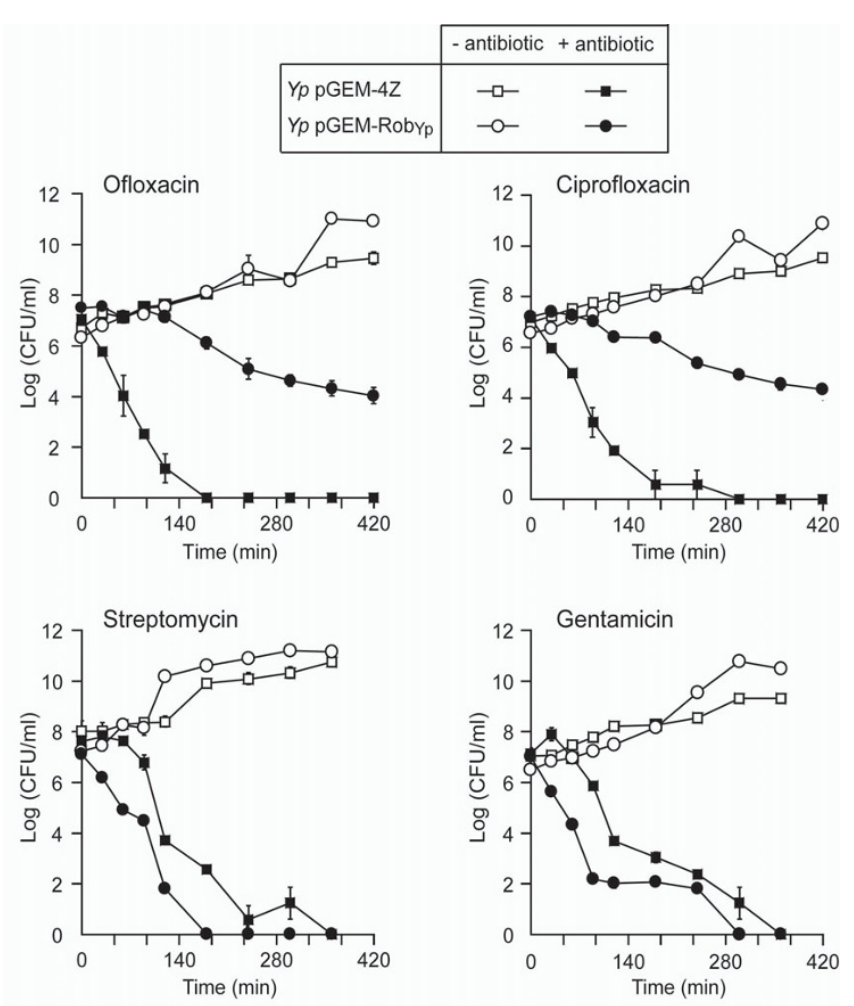

Figure 3

Effect of robA ${ }_{Y p}$ overexpression on the rate of $Y$. pestis killing by fluoroquinolones and aminoglycosides. $Y p$ pGEM-Rob ${ }_{Y p}$ (overexpressing rob $A_{Y P}$ ) and $Y_{P}$ PGEM-4Z (vector control) were treated with the indicated antibiotics at 5 $\times \mathrm{MIC}_{99}$. The means of triplicate treated cultures were plotted and standard error bars are shown.

what unexpected and contrasts with both the reduced susceptibility observed for all other antibiotics tested and the increased tolerance to organic solvents described below.

\section{Overexpression of robA $A_{Y p}$ increases tolerance to organic solvents}

We investigated whether $r o b A_{\mathrm{Yp}}$ overexpression affected the susceptibility of $\mathrm{Yp}$ and $\mathrm{Ec}$ to $\mathrm{O}_{2} \cdot$--generating compounds (paraquat, menadione, and plumbagin), heavy metals (zinc, cobalt, and copper), and organic solvents ( $n$ pentane, $n$-hexane, cyclohexane, $p$-xylene, and diphenyl ether). No effect on the susceptibility to $\mathrm{O}_{2}$---generating compounds, cobalt, and copper was observed (not shown). Conversely, overexpression of rob $A_{\mathrm{Yp}}$ drastically increased organic solvent tolerance in both $Y p$ and $E c$ (Figure 4) and reduced the susceptibility of $Y p$ to zinc (not shown). Overexpression of $r o b A_{\mathrm{Yp}}$ increased the tolerance of $Y p$ to $n$-hexane and cyclohexane and the tolerance of $E c$ to cyclohexane and $n$-pentane. All the $Y p$ and $E c$ strains were resistant to diphenyl ether and sensitive to $p$-xylene. $E c$ was also resistant to $n$-hexane, a result that is in agree-

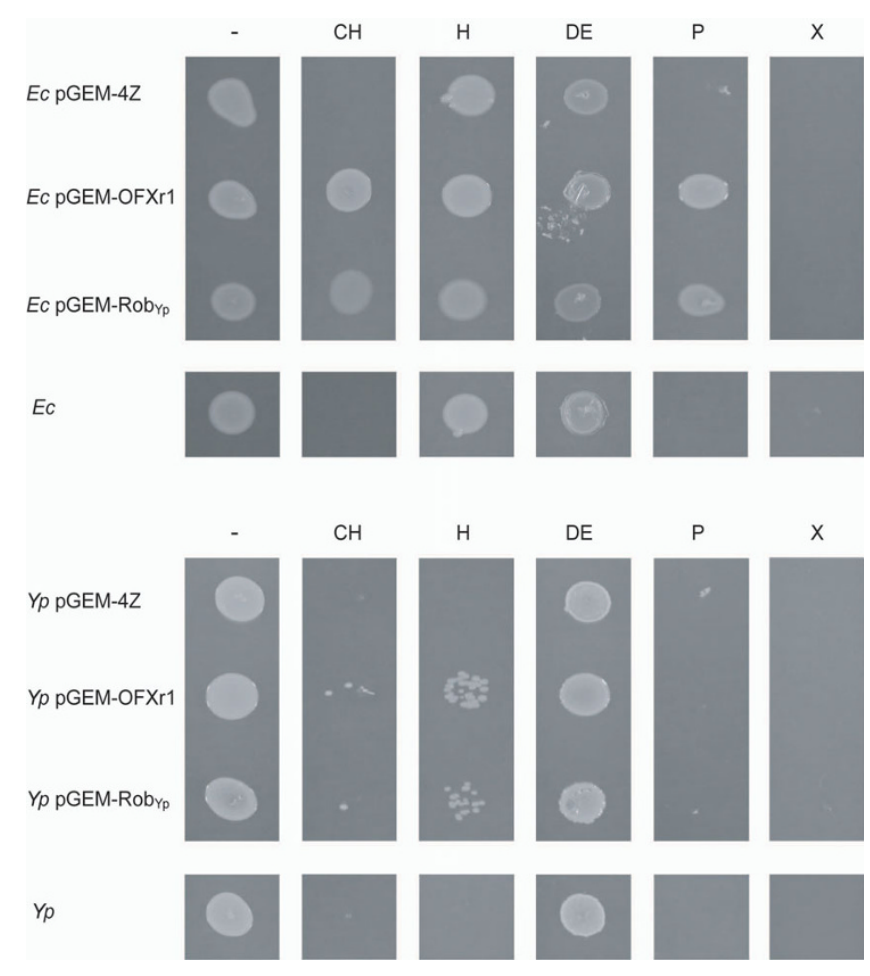

Figure 4

Effect of robA $A_{Y p}$ overexpression on organic solvent tolerance. Cultures of $Y$. pestis $(Y p)$ and $E$. coli $(E c)$ strains carrying the plasmids indicated were spotted on solid medium. The surface of the medium was overlaid with the organic solvent and growth was recorded after incubation. $\mathrm{H}$, $n$-hexane; $\mathrm{CH}$, cyclohexane; $\mathrm{P}, n$-pentane; $\mathrm{X}, \mathrm{p}$-xylene; $\mathrm{DE}$, diphenyl ether; -, no solvent control.

ment with previous reports [24]. These findings parallel the reduction of organic solvent susceptibility induced by $r o b A_{\mathrm{Ec}}$ overexpression in $E c$ [21].

\section{Overexpression of rob $A_{Y_{p}}$ in $Y$. pestis induces changes in efflux pump gene expression}

In $E c$, the RobA $_{\mathrm{Ec}}$-induced multidrug resistance and solvent tolerance phenotypes have been shown to be largely dependent on the upregulation of the multidrug efflux pump AcrAB, which belongs to the resistance-nodulationcell division (RND) superfamily $[25,26]$. With this precedent in mind, we compared the expression of genes belonging to 34 drug efflux pumps between $Y p$ pGEMRob $_{\mathrm{Yp}}$ and $Y p$ pGEM-4Z using quantitative real-time PCR (qRT-PCR). These pumps were identified using a variety of bioinformatic approaches (see Methods) to compile an extensive list that included most, if not all, putative drug efflux pump systems encoded in the genome of $Y p$. It is worth mentioning as a reference that there are 37 drug efflux pumps annotated in the Ec genome [27,28]. Our expression analysis detected transcripts for 33 of the 34 genes investigated and revealed that four efflux pumps 
Table 2: Effect of robA $A_{Y p}$ overexpression on the transcript levels of efflux pump genes in $Y$. pestis

\begin{tabular}{|c|c|c|c|c|c|}
\hline Gene name $^{a}$ & University of Wisconsin b & TIGR & SANGER & Pump family or protein functionc & $\mathrm{FCd}^{\mathrm{d}}$ \\
\hline$(f l o R)$ & y2 I 73 & NT02YP2579 & YPO2|48 & MFS & $12.7 \pm 2.5$ \\
\hline (yieO) & y0010 & NT02YP00IO & YPO0009 & MFS & $8.6 \pm I . I$ \\
\hline$(a c r A *-a c r B)$ & y3392*-y3393 & NT02YP404I & YPOI000 & RND & $6.9 \pm 0.4$ \\
\hline$a c r A^{*}-a c r B$ & y1050*-y1049 & NT02YPI 227 & YPO3I32 & RND & $5.0 \pm 0.4$ \\
\hline$\left(a c r A^{*}-a c r B\right)$ & y3760*-y3759 & NT02YP4463 & YPO0420 & RND & $2.7 \pm 0.1$ \\
\hline- & $y 4041$ & NT02YP4789 & YPO4020 & DMT & $1.7 \pm 0.9$ \\
\hline yeg $M^{*}$-yeg $N$-yegO-yegB & y/386*-y/385-y /384-y/383 & NT02YPI646 & YPO2847 & RND & $1.4 \pm 0.5$ \\
\hline$\left(y b j Y^{*}-y b j Z\right)$ & y2814*-y2813 & NT02YP3366 & YPOI364 & $A B C$ & $1.4 \pm 0.4$ \\
\hline$(a c r A *-a c r B)$ & y0702*-y0703 & NT02YP0804 & YPO3483 & RND & $1.3 \pm 0.3$ \\
\hline emrA*-emrB & y0922*-y092I & NT02YPI066 & YPO3267 & MFS & $1.3 \pm 0.4$ \\
\hline$\left(m a c A^{*}-m a c B\right)$ & $y|48 I *-y| 480$ & NT02YPI756 & YPO2999 & RND & $1.3 \pm 0.5$ \\
\hline ygeD & $y 3180$ & NT02YP3786 & YPO0792 & MFS & $1.3 \pm 0.2$ \\
\hline fieF & y0060 & NT02YP0067 & YPO0077 & CDF & $1.2 \pm 0.1$ \\
\hline$(a b g T)$ & y3402 & NT02YP4052 & YPOI008 & $\mathrm{IT}$ & $1.1 \pm 0.2$ \\
\hline acrD & $y / 439$ & NT02YPI705 & YPO3043 & RND & $I . I \pm 0.1$ \\
\hline sugE & y06/3 & NT02YP0702 & YPO0355 & SMR & $1.1 \pm 0.4$ \\
\hline (ynfM) & y2 108 & NT02YP2497 & YPO2266 & MFS & $1.1 \pm 0.4$ \\
\hline bcr & y2916 & NT02YP3488 & YPOI267 & MFS & $1.1 \pm 0.3$ \\
\hline$a a e{ }^{*}$-aaeB & y0178*-y0177 & NT02YP0I92 & YPO3685 & ArAE & $1.1 \pm 0.0$ \\
\hline$\left(y j c R^{*}-Q\right)$ & y3558*-y3559 & NT02YP423I & YPO0619 & RND & $1.0 \pm 0.2$ \\
\hline yajR & y1017 & NT02YPII87 & YPO3I69 & MFS & $1.0 \pm 0.1$ \\
\hline $\operatorname{ars} B$ & y0844 & NT02YP0968 & YPO3347 & IT & $1.0 \pm 0.4$ \\
\hline $\operatorname{cor} C$ & $y / 191$ & NT02YPI397 & YPO26I7 & $\mathrm{HCC}$ & $0.9 \pm 0.1$ \\
\hline$m d t]^{*}-m d t l$ & y2242*-y224I & NT02YP2670 & YPO2068 & SMR & $0.8 \pm 0.2$ \\
\hline $\operatorname{ros} A$ & y 1087 & NT02YPI268 & YPO3093 & MFS & $0.8 \pm 0.1$ \\
\hline \multirow[t]{2}{*}{$y d h C$} & y/948 & NT02YP2306 & YPO2389 & MFS & $0.8 \pm 0.2$ \\
\hline & y3/86 & NT02YP3792 & YPO0798 & MFS & $0.7 \pm 0.1$ \\
\hline$(y d h E)$ & y1945 & NT02YP2302 & YPO2392 & MATE & $0.7 \pm 0.1$ \\
\hline$(y b e Q)$ & $y / 874$ & NT02YP2220 & YPOI7I2 & MFS & $0.7 \pm 0.0$ \\
\hline$m d \mid A *-m d I B$ & y1039*-y1040 & NT02YPI2I3 & YPO3।45 & $A B C$ & $0.7 \pm 0.0$ \\
\hline ydeF & y2653 & NT02YP3I 68 & YPOI5I5 & MFS & $0.5 \pm 0.1$ \\
\hline emrE, gacE & y2000 & NT02YP2368 & YPO2333 & SMR & $0.5 \pm 0.0$ \\
\hline$m d f A, c m r$ & y4067 & NT02YP4824 & YPO4048 & MFS & $0.2 \pm 0.0$ \\
\hline (ydjv) & y2272 & NT02YP2703 & YPO2040 & MFS & nd \\
\hline
\end{tabular}

a Gene name as annotated for $Y$. pestis strain KIM and/or CO92 or gene names (in parentheses) given herein based on the name of their E. coli homologs. Multiple names for the same gene are separated by commas. Genes of multi-component pumps are separated by dashes. The star $(*)$ marks genes from multi-component pump gene clusters whose transcripts were analyzed by qRT-PCR. ${ }^{b}$ Gene designations in the University of Wisconsin, TIGR, and SANGER Y. pestis genome databases. The Wisconsin column shows designations for all the genes in each predicted multicomponent pump. TIGR and SANGER columns show only genes targeted in qRT-PCR. c Pump families assigned based on homology to known (super)family members from other organisms. MFS, major facilitator superfamily; SMR, small multidrug resistance family; ABC, ATP-binding cassette superfamily; RND, resistance-nodulation-cell division superfamily; MATE, multidrug and toxic compound extrusion family; DMT, drug/metabolite transporter superfamily; CDF, cation diffusion facilitator family; ArAE, aromatic acid exporter family; IT, lon transporter superfamily; HCC, HlyC/ CorC family. $d$ Fold change values (FC) are means of triplicates \pm standard errors and are presented in decreasing order. For polycistronic transcripts, qRT-PCR was conducted with primers targeting the first pump component-encoding gene of the operon. These genes are marked with a star. nd, transcript not detected in any of the three $Y$. pestis strains examined (wild-type, $Y_{P} p G E M-4 Z$, and $Y_{P} p G E M-R o b Y_{P}$ ).

were significantly upregulated $(\geq 5$-fold change) in $Y p$ pGEM-Rob ${ }_{\mathrm{Yp}}$ compared with Yp pGEM-4Z (Table 2). Interestingly, two of these upregulated pumps ( $\gamma 3392-$ y3393 and $y 1050-y 1049)$ are Ec AcrAB homologs. The other two upregulated pumps ( $y 2173$ and y0010) belong to the major facilitator superfamily (MFS). The transcript level of hasF (y3516), encoding the ortholog of Ec TolC, which is the outer membrane protein channel that partners with Ec AcrAB and other RND and MFS pumps $[29,30]$, was drastically upregulated as well (5.8-fold change; not shown).
Inspection of the promoter regions upstream of the upregulated genes in $Y p$ pGEM-Rob ${ }_{\mathrm{Yp}}$ revealed the presence of a putative RobA $\mathrm{Ec}_{\mathrm{C}}$ binding site in each of these regions (Figure 5). These results suggest that $\operatorname{Rob}_{\mathrm{Yp}}$ may act as a positive regulator for the $\gamma 0010, y 1050-y 1049, y 2173$ and y3392-y3393 systems. This possible regulatory scenario is consistent with the upregulation in the expression levels of these pumps induced by rob $A_{\mathrm{Yp}}$ overexpression in $Y p$.

It is likely that the multidrug resistance and solvent tolerance phenotypes induced by rob $A_{\mathrm{Yp}}$ overexpression are 


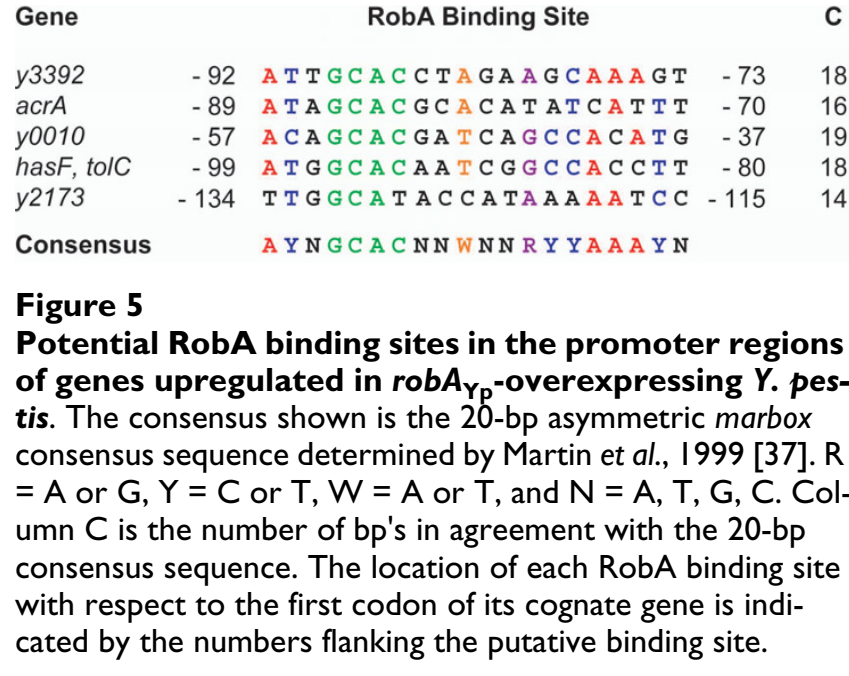

due, at least in part, to increases in compound extrusion by one or more of the upregulated pumps mentioned above. This idea is supported by the reported observation that the $\mathrm{RobA}_{\mathrm{Ec}}$-induced multidrug resistance and solvent tolerance in $E c$ is largely dependent on the AcrAB-TolC efflux pump system $[25,26]$.

\section{Conclusion}

The identification of $Y p$ genes that, when overexpressed, are capable of reducing antibiotic susceptibility is a useful strategy to expose genes that this pathogen may rely upon to evolve resistance via a vertical modality. In this study, we explored the use of a multicopy suppressor, $E c$ hostbased screening approach as a means to identify antibiotic resistance determinant candidates in $Y p$. To seek proof of principle for this approach, we constructed a multicopy plasmid-based, $Y p$ genome-wide expression library of nearly 16,000 clones in $E c$ and screened this library for suppressors of the antimicrobial activity of the fluoroquinolone antibiotic OFX. The screen permitted the identification of a gene that, when overexpressed, reduces the susceptibility of $Y p$ not only to OFX, but also to other (fluoro)quinolones, tetracyclines and CHL. This gene $\left(r o b A_{\mathrm{Yp}}\right)$ encodes a putative transcriptional regulator, and our results clearly demonstrate that its overexpression in $Y p$ and $E c$ confers low-level resistance to multiple antibiotics. Overexpression of $r o b A_{\mathrm{YP}}$ also increases organic solvent tolerance in both $Y p$ and $E c$ and reduces the susceptibility of $Y p$ to zinc.

The molecular mechanism by which overexpression of $r o b A_{\mathrm{Yp}}$ leads to a reduction in the susceptibility to antibiotics and other compounds remains to be determined. Our results indicate that overexpression of $r o b A_{\mathrm{Yp}}$ induces a drastic upregulation in the transcript levels of four of the 34 predicted efflux pump gene systems and of hasF ( $t o l C)$ in $Y p$. Increased expression of chromosomally encoded efflux pumps is a known cause of multidrug resistance in many bacteria [30]. Thus, it is likely that the reduction in the susceptibility to antibiotics and other compounds induced by rob $A_{\mathrm{Yp}}$ overexpression is due, at least in part, to multidrug efflux pump-mediated increases in compound extrusion.

Overall, our findings provide proof of principle for the utilization of an $E c$ host-based suppressor screen to identify antibiotic resistance determinant candidates in $Y p$. This methodology will be useful in the identification of genetic determinants involved in target-dependent and target-independent resistance to antimicrobials with known and unknown mechanisms of action. Identification of such genetic determinants will provide first insights to guide further studies to obtain mechanistic information on novel modes of antimicrobial activity and antimicrobial resistance.

\section{Methods}

\section{Construction of genomic library}

Unless otherwise indicated, all molecular biology and microbiological manipulations were conducted using standard procedures [31] and reagents acquired from New England Biolabs or Sigma-Aldrich. Genomic DNA from the avirulent $Y p$ strain KIM6+ [32] was used for the library. This strain lacks the Lcr virulence plasmid [5] and is excluded from the Select Agent Program (please see Availability \& requirements for more details). Genomic DNA was prepared using AquaPure ${ }^{\mathrm{TM}}$ Genomic DNA Isolation Kit (Bio-Rad Laboratories) and partially digested with $B s r F I$, which, on average, cleaves the genome of $Y p$ every $\sim 760 \mathrm{bp}$. Independent partial digestions were resolved by agarose gel electrophoresis and the fragment populations in the 4,000-bp to 8,000-bp range were purified using QIAquick Gel Extraction Kit (Qiagen). The fragments were ligated to the multicopy plasmid vector pGEM-4Z (Promega) linearized with XmaI and dephosphorylated with calf intestine alkaline phosphatase. Genes inserted into pGEM- $4 \mathrm{Z}$ can be transcribed from the gpt-lac hybrid promoter located at the 5 '-end of the cloning site and, potentially, from their native promoters. Ligations were transformed into Ec DH5a (Invitrogen) and transformants were selected in Luria-Bertani (LB) agar plates containing AMP $(100 \mu \mathrm{g} / \mathrm{ml})$ and 5-bromo-4-chloro-3indolyl- $\beta$-D-galactopyranoside $(40 \mu \mathrm{g} / \mathrm{ml})$ for blue/white colony screening [31]. White colonies were streaked onto the same medium to verify their white phenotype and 15,648 confirmed white clones were independently grown in AMP-containing LB broth in 96-well plates. After plate incubation for culture growth to early stationary phase, aliquots from each of the 96 cultures of each plate were pooled, cells from each pool were harvested, and plasmids from each pool were purified using QIAprep Spin Miniprep Kit (Qiagen). The cultures in the plates 
were supplemented with glycerol (25\%) and this master library was stored at $-70^{\circ} \mathrm{C}$. Agarose gel electrophoresis analysis confirmed plasmid population heterogeneity and restriction digestion analysis of plasmids from several clones verified insert diversity (not shown). The library provides a theoretical 760-fold genome coverage. Our in silico BsrFI restriction analysis of the $Y p$ genome revealed the presence of four BsrFI fragments of $\geq 8,000 \mathrm{bp}$. These fragments, which add up to $39,118 \mathrm{bp}$, are unlikely to be represented in the library.

\section{Multicopy suppressor screening}

The library was replicated using a 96-pin inoculator (Clonemaster ${ }^{\mathrm{TM}}$; Immusine Laboratories, Inc.) to inoculate 96-well plates loaded with fresh culture medium $(150 \mu \mathrm{l} /$ well). After plate incubation for culture growth $(9 \mathrm{~h}$, $37^{\circ} \mathrm{C}, 200 \mathrm{rpm}$ ), the 15,648 cultures were pooled and the cells of the pool were harvested. The pooled cells were resuspended in fresh medium $(1 / 10 \times$ pool's volume $)$ containing AMP $(100 \mu \mathrm{g} / \mathrm{ml})$ and glycerol $(25 \%)$, and the suspension was aliquoted ( $1 \mathrm{ml}$ library stock aliquots) and stored at $-70^{\circ} \mathrm{C}$. Multicopy suppressor gene-containing clones were screened for by plating a $1 / 100$ dilution of a library stock aliquot on LB agar plates containing AMP $(100 \mu \mathrm{g} / \mathrm{ml})$ and OFX at the MIC $(0.35 \mu \mathrm{g} / \mathrm{ml})$. The OFX MIC was determined by plating Ec carrying pGEM-4Z (Ec pGEM-4Z) on LB agar plates containing AMP $(100 \mu \mathrm{g} / \mathrm{ml})$ and OFX at increasing concentrations and defined as the concentration for which no colonies were obseved after plate incubation $\left(37^{\circ} \mathrm{C}, 48 \mathrm{~h}\right)$. Clones identified in the screen were streaked on plates containing AMP $(100 \mu \mathrm{g} /$ $\mathrm{ml})$ and OFX $(0.35 \mu \mathrm{g} / \mathrm{ml})$ to confirm their resistant phenotype. The plasmid from each confirmed clone was isolated and transformed into $E c$ and $Y p$. Each transformant was streaked on AMP and OFX-containing plates [LB agar for $E c$ and tryptose blood agar base (TBA; Difco Laboratories) for $Y p$ ] to ascertain whether the resistance was plasmid mediated. The insert of each plasmid conferring resistance was sequenced using M13 forward and reverse universal primers (Invitrogen). The sequences obtained were used as queries in sequence similarity searches against the Yp KIM genome using BLAST (please see Availability $\&$ requirements for more details) to determine the genome fragment carried by the plasmid.

\section{Construction of PGEM-Rob ${ }_{Y p}$ and transformation of $Y$. pestis}

The fragment encompassing Yp robA (herein referred to as $r o b A_{\mathrm{YP}}$ ) and its promoter region was PCR-amplified from plasmid pGEM-OFXr1 (see results) with primers Robfor1 and Robrev1 (Table 3 ). The PCR product (1030 bp) was cloned into pCR2.1-TOPO (TOPO TA Cloning Kit, Invitrogen) and the fidelity of the insert was verified by DNA sequencing. The insert was recovered from the pCR2.1TOPO clone as an EcoRI fragment and sub-cloned into the
Table 3: Oligonucleotides used in this study

\begin{tabular}{|c|c|}
\hline Name $^{a}$ & Sequence \\
\hline Robforl & 5'-TCTAGACGCTTTTTTAACACACTGTACCAGT-3' \\
\hline Robrevl & 5'-GAATTCATTTAGATATGCCAGCACTTGATGA-3' \\
\hline 16sRNAF & 5'-ATGACCAGCCACACTGGAACTGA-3' \\
\hline I6sRNAR & 5'-TGACTTAACAAACCGCCTGCGT-3' \\
\hline y3392F & 5'-AGCGGCACCTTGGTCAATATTGT-3' \\
\hline y3392R & 5'-CAATTTGGTTATCCACCGATTCA-3' \\
\hline yl050F & 5'-GCTTATGACAGTGCAAAAGGTGA-3' \\
\hline y $1050 R$ & 5'-GATTAATGCGTGCAGACTCCAGT-3' \\
\hline y0702F & 5'-TATACCCAAGTGCGGGCACCCAT-3' \\
\hline y0702R & 5'-CATTCGCTACTGTGTCATTGCCT-3' \\
\hline y3402F & 5'-TCGATGCCACTGAATAGCGATCT-3' \\
\hline y3402R & 5'-ATCTGGTGAACGCAATAACGAGT-3' \\
\hline yl439F & 5'-CAGCCATCAAGAGGCTGCCCCAA-3' \\
\hline yl439R & 5'-ACCAAAGGCATCGACGCTGCCGA-3' \\
\hline y $1087 F$ & 5'-GGTGCTATCAGCGTATCTCACCT-3' \\
\hline y $1087 R$ & 5'-CCATACCGATGGGTAATGAGTAT-3' \\
\hline y0060F & 5'-GCAACCTGCTGATGAAGAACATA-3' \\
\hline y0060R & 5'-CACGAATCGCCTGACTGTGTGTT-3' \\
\hline y0844F & 5'-CGTTGCTAAACCGACTGGGTGAA-3' \\
\hline y0844R & 5'-TTGCGACAAAACATGCAGCCACA-3' \\
\hline y0922F & 5'-CGGCAGTGTGGTCAGTGTTCATT-3' \\
\hline y0922R & 5'-CACCCGACGCTTCAGGTCATTTTT-3' \\
\hline yIIIIF & 5'-TCCTTAACCAGCTCTTCCACGGT-3' \\
\hline YIIIIR & 5'-CTTTATCTTCGCTGATCACCGGA-3' \\
\hline yl386F & 5'-GTGGTCAGGACACTAGCCATGGT-3' \\
\hline yl386R & 5'-CCTGCGTCAGTTGGACTTCGTAA-3' \\
\hline yl48IF & 5'-AAAGCACAGAAGCAGGTGACTGT-3' \\
\hline$y \mid 48 I R$ & 5'-TTGTTGCTGACGCTGGTAGGTGA-3' \\
\hline y $1874 \mathrm{~F}$ & 5'-TTACCGACTATCGCACGTGACCT-3' \\
\hline y $1874 R$ & 5'-TTGTAGCACACGGGCAAACGTCA-3' \\
\hline yl945F & 5'-CCTGATGATGAGATGGTACGTAA-3' \\
\hline yl945R & 5'-TGAACTGAAGTTGAGGGCAATCT-3' \\
\hline y $2242 F$ & 5'-TTTAGTGACACTGATTGGTGGGA-3' \\
\hline y $2242 R$ & 5'-CATGATGCTCACCTGACTCAACA-3' \\
\hline y3180F & 5'-GGTAATGATGGTGGCTAATGGTT-3' \\
\hline Y3 $3180 R$ & 5'-CAACCGAGCCAAGTAAGATCGCA-3' \\
\hline y3558F & 5'-GCCATTGATCCTGTTATCGGCTA-3' \\
\hline y3558R & 5'-ATAGGGAACAGATGAATGCCACA-3' \\
\hline y $404 \mathrm{IF}$ & 5'-TTACGACCACAACGGTAGATGAA-3' \\
\hline y404IR & 5'-CATTGGTGCGGCAAGGTTCATAT-3' \\
\hline y4067F & 5'-GATATGATCCAGCCAGGTATGCT-3' \\
\hline y4067R & 5'-GCACCGATAAAGCACAAGCCAAT-3' \\
\hline yOOIOF & 5'-TCGCCGAAAGCCTTAACCGTTCT-3' \\
\hline YOOIOR & 5'-CCGAGAACGCACTAAGAAAGCCA-3' \\
\hline y0178F & 5'-TTTACCGCAGACGTGGTCGCTAT-3' \\
\hline$y 0178 R$ & 5'-CCTACTGGACTCCCGTTGCTTCT-3' \\
\hline$y 0613 F$ & 5'-GGGCTATTGGCCTGAAGTATTCT-3' \\
\hline y06I3R & 5'-AAGCTTAGTATCCGCGCCAGACT-3' \\
\hline y1017F & 5'-AAATGACTCCGCTAGAGCTTCGA-3' \\
\hline y $1017 R$ & 5'-GGTTTACGACCGATACGATCAGA-3' \\
\hline yl039F & 5'-GCCGTGAATGGCACCGTTATGTA-3' \\
\hline y1039R & 5'-AGTTTGCCGACTCAGCTGACGAT-3' \\
\hline yl948F & 5'-CTGCCTGTAGTGCTGGCTTCTTT-3' \\
\hline yl948R & 5'-AGTACAGGGCAATCATGCTGCCA-3' \\
\hline y2000F & 5'-TGGCGATTATTGCCGAAGTGGTT-3' \\
\hline y2000R & 5'-AAAGGTGGCAGCGATTGAGACCA-3' \\
\hline y $2108 F$ & 5'-GGTTGTATATCAGCGGTAGTTCT-3' \\
\hline y2108R & 5'-TTGCACGAAAGTGTTTAGACGCT-3' \\
\hline y2173F & 5'-ACAAGGTGTCTCGGTATGCTGCA-3' \\
\hline
\end{tabular}


EcoRI site of pGEM-4Z using Ec DH5 $\alpha$ as host. A clone with $r o b A_{\mathrm{Yp}}$ in the same orientation as the lac $Z$ gene of pGEM-4Z was designated pGEM-Rob ${ }_{Y \mathrm{p}}$. pGEM-Rob $\mathrm{b}_{\mathrm{Yp}}$ and pGEM-4Z were introduced into avirulent $Y p$ by electroporation as reported earlier [33] to create strains $Y p$ pGEMRob $_{Y p}$ and $Y p$ pGEM-4Z, respectively. Yp strains were grown in heart infusion broth (HIB; Difco Laboratories) and on TBA plates without or with antibiotics as appropriate.

\section{$M I C_{99}$ and $I C_{50}$ determinations}

Dose-response experiments were done in triplicate and using 96 well plate-based microdilution assays as reported $[12,14]$. Briefly, wells contained $200 \mu \mathrm{l}$ of broth (LB for $E c$, HIB for $Y p$ ) inoculated with $10^{4} \mathrm{cfu} / \mathrm{ml}$ and supplemented with AMP $(100 \mu \mathrm{g} / \mathrm{ml})$ and a second antimicrobial compound at the concentration indicated below. Antimicrobial compounds were added from stock solutions in water, ethanol, or DMSO. Control cultures lacking the antimicrobial compounds contained water $(2 \%)$, ethanol $(1 \%)$, or DMSO (0.5\%). After incubation $\left(37^{\circ} \mathrm{C}, 200\right.$ rpm, $24 \mathrm{~h}$ for $Y p$ and $16 \mathrm{~h}$ for $E c)$, growth was measured as optical density $\left(A_{620}\right)$ using a Spectra Max Plus spectrophotometer plate reader (Molecular Dynamics). $\mathrm{IC}_{50}$ values were calculated from sigmoidal curves fitted to triplicate sets of dose-response data using KaleidaGraph (Synergy Software). MIC $_{99}$ values were calculated as the lowest concentration tested that inhibited growth by $\geq$ $99 \%$. The range of concentrations tested were: OFX (Sigma), 2.5-0.001 $\mu \mathrm{g} / \mathrm{ml}$; KAN (Shelton Scientific), 50$0.024 \mu \mathrm{g} / \mathrm{ml} ;$ CHL (Calbiochem), $10-0.005 \mu \mathrm{g} / \mathrm{ml}$ for $Y p$ and $25-0.012 \mu \mathrm{g} / \mathrm{ml}$ for Ec; TET (Sigma), 40-0.020 $\mu \mathrm{g} / \mathrm{ml}$; APR (Sigma), 50-0.024 $\mu \mathrm{g} / \mathrm{ml}$; NAL (Sigma), 25-0.012 $\mu \mathrm{g} /$ $\mathrm{ml}$ for $Y p$ and $400-0.195 \mu \mathrm{g} / \mathrm{ml}$ for $E c$; STR (Sigma), 50$0.024 \mu \mathrm{g} / \mathrm{ml}$ for $Y p$ and $100-0.049 \mu \mathrm{g} / \mathrm{ml}$ for Ec; GEN (EM Science), $25-0.012 \mu \mathrm{g} / \mathrm{ml}$ for $Y p$ and $50-0.024 \mu \mathrm{g} / \mathrm{ml}$ for Ec; DOX (Sigma), 10-0.005 $\mu \mathrm{g} / \mathrm{ml}$; CIP (Fluka), 0.75$0.0004 \mu \mathrm{g} / \mathrm{ml}$ for $Y p$ and $1.25-0.0006 \mu \mathrm{g} / \mathrm{ml}$ for $E c$; LVX (Fluka), $0.75-0.0004 \mu \mathrm{g} / \mathrm{ml}$ for $Y p$ and $1.25-0.0006 \mu \mathrm{g} / \mathrm{ml}$ for $E c$; plumbagin (Sigma), 50-0.024 $\mu \mathrm{g} / \mathrm{ml}$ for $Y p$ and $200-0.098 \mu \mathrm{g} / \mathrm{ml}$ for $E c$; menadione (Sigma), 50-0.024 $\mu \mathrm{g} / \mathrm{ml}$ for $Y p$ and $400-0.195 \mu \mathrm{g} / \mathrm{ml}$ for $E c$; paraquat (Sigma), 200-0.098 $\mu \mathrm{g} / \mathrm{ml}$ for $Y p$ and 400-0.195 $\mu \mathrm{g} / \mathrm{ml}$ for Ec; $\mathrm{CoCl}_{2}$ (Sigma), 1-0.0005 mg/ml; $\mathrm{CuSO}_{4}$ (Sigma), 2$0.001 \mathrm{mg} / \mathrm{ml}$ for $Y p$ and $4-0.002 \mathrm{mg} / \mathrm{ml}$ for $E c ; \mathrm{ZnCl}_{2}$ (Sigma), 1-0.0005 mg/ml.

\section{Organic solvent tolerance assay}

The test for solvent tolerance was conducted essentially as reported previously [21]. Overnight cultures of Ec and Yp strains grown in LB broth and HIB, respectively, were inoculated (1\%) into fresh media and allowed to grow to $A_{620}=0.4$. Then, $5 \mu \mathrm{l}$ of each culture were spotted on solid medium (LB agar for Ec, TBA for $Y p$ ) with $100 \mu \mathrm{g} / \mathrm{ml}$ AMP for transformants carrying pGEM plasmids or without
Table 3: Oligonucleotides used in this study (Continued)

\begin{tabular}{ll}
\hline y2173R & 5'-ATAATGCCAGGAACCAGAACGCT-3' \\
y2272F & 5'-TTGGTATCGCAAGCTCGAAGCTT-3' \\
y2272R & 5'-TCGCATTAGCATCCCGGTGACAA-3' \\
y2653F & 5'-ATGACCGTCAATGCGACCATCGT-3' \\
y2653R & 5'-AATGGCCATTGCCAGCATCCATA-3' \\
y28I4F & 5'-TCTGGACCAGGCAGTAACCGATT-3' \\
y28I4R & 5'-TACTCATATCGGCCAGGGTCAGA-3' \\
y2916F & 5'-CCTTGGGTTGTTGTCGATGCTGA-3' \\
y2916R & 5'-ACATGCCATACCTGCAAGCGCAA-3' \\
y3186F & 5'-GTCAGTTGGACGTTACTGCTAAT-3' \\
y3186R & 5'-CTTTCTTGCCATAAGCGACGACA-3' \\
y3760F & 5'-TCTGGATATTCGCCGTGCAGAGA-3' \\
y3760R & 5'-CGTGGTAAACAGACGCTCTGGAA-3' \\
y3516F & 5'-TGCAACGACTAACCTGTATCAGT-3' \\
y3516R & 5'-TTTGGCGAGTAGTATTCTCTGGT-3'
\end{tabular}

a Primers used for qRT-PCR were named according to the University of Wisconsin gene designations for the $Y$. pestis KIM genome, except for 16sRNAF-R (used to amplify 16s rRNA).

antibiotic for other strains. The surface of the medium was then overlaid with the organic solvent $(7 \mathrm{ml})$ to a thickness of $3 \mathrm{~mm}$. The plates were sealed and incubated for $24 \mathrm{~h}$ for Ec strains and $48 \mathrm{~h}$ for $Y p$ strains before naked-eye examination for bacterial growth.

\section{Time-kill experiments}

$Y p$ pGEM-Rob ${ }_{\mathrm{Yp}}$ and $Y p$ pGEM-4Z (control) were treated with STR, GEN, OFX, or CIP at $5 \times \mathrm{MIC}_{99}$. The $\mathrm{MIC}_{99}$ values were those determined using $Y p$ pGEM-4Z in the doseresponse experiments above $\left(5 \times \mathrm{MIC}_{99}\right.$ values: $\mathrm{STR}, 15.6$ $\mu \mathrm{g} / \mathrm{ml} ; \mathrm{GEN}, 5.2 \mu \mathrm{g} / \mathrm{ml}$; OFX, $0.17 \mu \mathrm{g} / \mathrm{ml}$; CIP, $0.12 \mu \mathrm{g} /$ $\mathrm{ml}$ ). For each antibiotic tested, three tubes with $10 \mathrm{ml}$ of preheated $\left(37^{\circ} \mathrm{C}\right) \mathrm{HIB}$ containing AMP $(100 \mu \mathrm{g} / \mathrm{ml})$ were inoculated with $10 \mu \mathrm{l}$ of an overnight culture of the corresponding $Y p$ strain and incubated at $37^{\circ} \mathrm{C}$ with shaking at $200 \mathrm{rpm}$ for $2 \mathrm{~h}$. After incubation, a sample of each culture was taken and $\mathrm{cfu} / \mathrm{ml}$ were determined by plating serial dilutions on TBA plates containing AMP $(100 \mu \mathrm{g} / \mathrm{ml})$ and enumerating colonies after plate incubation. Immediately after culture sampling, the test antibiotic was added (from stock solutions in water for GEN and STR or stock solutions in DMSO for OFX and CIP) and the cultures were returned to incubation $\left(37^{\circ} \mathrm{C}, 200 \mathrm{rpm}\right)$. Samples from these cultures were then taken at time points 0 (immediately after antibiotic addition), 30, 60, 90, 120, 180, 240, 300,360 , and $420 \mathrm{~min}$ for $\mathrm{cfu} / \mathrm{ml}$ determination as above. Triplicate control cultures where water or DMSO was added in place of the antibiotic solution were included in the experiments and treated and analyzed in the same way as the antibiotic-treated cultures. The time-kill data were plotted using Kaleidagraph (Synergy software).

\section{Isolation of total RNA and qRT-PCR}

$Y p$ and $E c$ were cultured in HIB and LB broth, respectively. AMP $(100 \mu \mathrm{g} / \mathrm{ml})$ was added to the medium for strains carrying pGEM-Rob $\mathrm{Yp}_{\mathrm{P}}$ or pGEM-4Z. Cultures were incu- 
bated $\left(37^{\circ} \mathrm{C}, 200 \mathrm{rpm}\right)$ until they reached $A_{620}$ of $\sim 0.5$ before RNA was isolated using the RiboPure-Bacteria Kit (Ambion) according to the manufacturer's instructions. RNA was isolated from triplicate cultures and treated with DNase I (Ambion) (4 units, $37^{\circ} \mathrm{C}, 30 \mathrm{~min}$ ) in DNase I Buffer (Ambion). After the treatment, DNase I was inactivated by adding DNase Inactivation Reagent (Ambion) at $20 \%$ of the final volume of RNA treated. The inactivation was allowed to proceed at room temperature for $2 \mathrm{~min}$. The RNA sample was then centrifuged at maximum speed in a microcentrifuge for $1 \mathrm{~min}$ to pellet the inactivation reagent. The RNA was then transferred to a new RNasefree microcentrifuge tube. cDNA was prepared from each RNA sample using TaqMan ${ }^{\circledast}$ Reverse Transcription Reagents Kit (Applied Biosystems) according to the manufacturer's instructions. Each cDNA sample was analyzed in triplicate by qRT-PCR using SYBR $^{\circledast}$ Green Master Mix (Applied Biosystems) according to the manufacturer's instructions. cDNA was kept undiluted for qRT-PCR analysis of robA cDNA and diluted 1:5 for analysis of other cDNAs. qRT-PCR and target sequence relative quantification were carried out using a 384-multiwell platform with an ABI-PRISM 7900 HT Sequence Detection System (Applied Biosystems) as described previously [34,35]. The thermocycling program included 1 cycle of $95^{\circ} \mathrm{C}$ for 5 min followed by 40 cycles of $95^{\circ} \mathrm{C}$ for $30 \mathrm{sec}, 55^{\circ} \mathrm{C}$ for 30 sec, and $72^{\circ} \mathrm{C}$ for $1 \mathrm{~min}$. Relative quantification was conducted using the standard equation $2^{-\Delta \Delta \mathrm{CT}}\left\{\right.$ i.e. $2^{-}$[(CT of target CDNA in sample1-CT of $16 \mathrm{~S}$ rRNA cDNA in sample 1)-(CT of target CDNA in sample 2-CT of 16S rRNA cDNA in sample 2)] \} [36]. The equation expresses $\mathrm{n}$-fold difference of the target $\mathrm{cDNA}$ in the sample from the strain carrying pGEM-Rob $\mathrm{Y}_{\mathrm{Yp}}$ (sample 1) relative to the target $\mathrm{CDNA}$ in the sample from the strain carrying pGEM-4Z (sample 2, control) with normalization to an endogenous control (16S rRNA cDNA). The cycle threshold (CT) values utilized in the equation were the average of three independent cultures of the same strain, each analyzed in triplicate by qRT-PCR.

\section{Identification of putative drug efflux pumps and RobA ${ }_{Y p}$ binding sites}

Searches for efflux pumps were conducted in the sequenced genomes of Yp KIM and and Yp CO92 (please see Availability \& requirements for more details). The search included the following strategies. First, the tables of functional classes in the genome websites were examined for annotated pumps. Second, the navigator function in the Artemis genome viewer software (please see Availability \& requirements for more details) was used to search for the terms multidrug, efflux, transport, translocase, pump, and drug resistance as qualifiers in the annotated genome sequences. Third, the names of annotated $E c$ multidrug efflux pumps were used as search keywords using the navigator function in Artemis to find potential pumps not yet identified with the other strategies. Fourth, all putative pumps identified in Yp KIM were used as queries in BLASTP-based searches against the $Y p$ CO92 genome and vice versa. Fifth, annotated $E c$ multidrug efflux pumps were used as queries in BLASTP-based searches against the $Y p$ $\mathrm{KIM}$ and Yp CO92 genomes. Potential RobA $\mathrm{Ec}_{\mathrm{C}}$ binding sites were searched for using the navigator function in Artemis and the naked eye.

\section{Abbreviations}

AMP: ampicillin; APR: apramycin; CHL: chloramphenicol; CIP: ciprofloxacin; CT: cycle threshold; DOX: doxycycline; Ec: E. coli; GEN: gentamicin; HIB: heart infusion broth; KAN: kanamycin; LB: Luria-Bertani; LVX: levofloxacin; MDR: multidrug-resistant; MFS: major facilitator superfamily; NAL: nalidixic acid; OFX: ofloxacin; RND: resistance-nodulation-cell division; STR: streptomycin; TBA: tryptose blood agar base; TET: tetracycline; Yp: Y. pestis.

\section{Availability \& requirements}

CD-Search: http://www.ncbi.nlm.nih.gov/Structure/cdd/ $\underline{\text { cdd.shtml }}$

Select Agent Program: http://www.cdc.gov/od/sap/sap/ exclusion.htm

\section{BLAST: http://www.ncbi.nlm.nih.gov/blast/Blast.cgi}

Yersinia pestis KIM Genome Page: http://cmr.tigr.org/tigrscripts/CMR/GenomePage.cgi?org=ntyp02

University of Wisconsin E. Coli Genome Project: http:// www.genome.wisc.edu/sequencing/pestis.htm

Wellcome Trust, Sanger Institute, Yersinia pestis data: http://www.sanger.ac.uk/Projects/Y pestis/

Artemis genome viewer software: http:// www.sanger.ac.uk/Software/Artemis/

\section{Authors' contributions}

LENQ, KLS, and JAF conceived and designed the experiments. KLS, JAF, SMR, and FVF constructed the expression library. KLS and SMR screened the library. KLS carried out the gene expression analysis and bioinformatic-guided identification of efflux pump genes. KLS and RLM constructed all plasmids and strains and conducted the strain characterization experiments. All authors contributed to the preparation of the manuscript. LENQ and KLS wrote the final version of the manuscript. All authors read and approved the final version of the manuscript. LENQ directed and oversaw the project.

\section{Acknowledgements}

This work was supported in part by NIH grant Al056293-0I. LENQ is a Stavros S. Niarchos Scholar. The Department of Microbiology and Immunol- 
ogy acknowledges the support from the William Randolph Hearst

Foundation. We are grateful to Nidza Torres for her assistance with the multicopy suppressor screen.

\section{References}

I. Brubaker RR: Factors promoting acute and chronic diseases caused by yersiniae. Clin Microbiol Rev 1991, 4(3):309-324.

2. Inglesby TV, Dennis DT, Henderson DA, Bartlett JG, Ascher MS, Eitzen E, Fine AD, Friedlander AM, Hauer J, Koerner JF, Layton M, McDade J, Osterholm MT, O'Toole T, Parker G, Perl TM, Russell PK, Schoch-Spana M, Tonat K: Plague as a biological weapon: medical and public health management. Working Group on Civilian Biodefense. JAMA 2000, 283( I 7):228I-2290.

3. Medical management of biological casualties handbook. 3rd edition. Edited by: Eitzen E, Pavlin J, Cieslak T, Christopher G, Culpepper R. Fort Detrick, Frederick, MD , U.S. Army Medical Research Institute of Infectious Diseases; 1998.

4. NIAID: NIAID category A, B, and C priority pathogens (2007) [http://www3.niaid.nih.gov/topics/BiodefenseRelated/Biodefense/ research/CatA.htm].

5. Perry RD, Fetherston JD: Yersinia pestis--etiologic agent of plague. Clin Microbiol Rev 1997, I O(I):35-66.

6. Prentice MB, Rahalison L: Plague. Lancet 2007, 369(9568): I 196-1207.

7. World Health Organization. Human plague in 2000 and 2001. Wkly Epidemiol Rec 2004, 79:301-308.

8. Schrag SJ, Wiener P: Emerging infectious disease: what are the relative roles of ecology and evolution? Trends Ecol Evol 1995, 10:319-324.

9. Poland JD, Dennis DT: Treatment of plague. In Plague manual: epidemiology, distribution, surveillance and control Geneva , World Health Organization; 1999:55-62.

10. Greenfield RA, Bronze MS: Prevention and treatment of bacterial diseases caused by bacterial bioterrorism threat agents. Drug Discov Today 2003, 8( I 9):88|-888.

II. Galimand M, Guiyoule A, Gerbaud G, Rasoamanana B, Chanteau S, Carniel E, Courvalin P: Multidrug resistance in Yersinia pestis mediated by a transferable plasmid. $N$ Engl J Med 1997, 337(1 0):677-680.

12. Ferreras JA, Ryu JS, Di Lello F, Tan DS, Quadri LE: Small-molecule inhibition of siderophore biosynthesis in Mycobacterium tuberculosis and Yersinia pestis. Nat Chem Biol 2005, I(I):29-32.

13. Cisar JS, Ferreras JA, Soni RK, Quadri LE, Tan DS: Exploiting ligand conformation in selective inhibition of non-ribosomal peptide synthetase amino acid adenylation with designed macrocyclic small molecules. I Am Chem Soc 2007, I 29(25):7752-7753.

14. Stirrett KL, Ferreras JA, Jayaprakash V, Sinha BN, Ren T, Quadri LE: Small molecules with structural similarities to siderophores as novel antimicrobials against Mycobacterium tuberculosis and Yersinia pestis. Bioorg Med Chem Lett 2008, I 8:2662-2668.

15. Quadri LEN: Strategic paradigm shifts in the antimicrobial drug discovery process of the 2 I st century. Infect Disord Drug Targets 2007, 7(3):230-237.

16. Li X, Zolli-Juran M, Cechetto JD, Daigle DM, Wright GD, Brown ED: Multicopy suppressors for novel antibacterial compounds reveal targets and drug efflux susceptibility. Chem Biol 2004 I I ( I 0): |423-1430.

I7. Chung JH, Back JH, Park YI, Han YS: Biochemical characterization of a novel hypoxanthine/xanthine dNTP pyrophosphatase from Methanococcus jannaschii. Nucleic Acids Res 200I, 29(I4):3099-3107.

18. Zheng J, Singh VK, Jia Z: Identification of an ITPase/XTPase in Escherichia coli by structural and biochemical analysis. Struc ture 2005, I3(10): 1511-1520.

19. Jair KW, Yu X, Skarstad K, Thony B, Fujita N, Ishihama A, Wolf RE Jr.: Transcriptional activation of promoters of the superoxide and multiple antibiotic resistance regulons by Rob, a binding protein of the Escherichia coli origin of chromosomal replication. J Bacteriol 1996, I 78(9):2507-25।3.

20. Ariza RR, Li Z, Ringstad N, Demple B: Activation of multiple antibiotic resistance and binding of stress-inducible promoters by Escherichia coli Rob protein. I Bacteriol 1995, I77(7): |655-|66I.
21. Nakajima H, Kobayashi K, Kobayashi M, Asako H, Aono R: Overexpression of the robA gene increases organic solvent tolerance and multiple antibiotic and heavy metal ion resistance in Escherichia coli. Appl Environ Microbiol 1995, 6 I (6):2302-2307.

22. Lee EH, Collatz E, Podglajen I, Gutmann L: A rob-like gene of Enterobacter cloacae affecting porin synthesis and susceptibility to multiple antibiotics. Antimicrob Agents Chemother 1996 , 40(9):2029-2033

23. Schneiders T, Levy SB: MarA-mediated transcriptional repression of the rob promoter. J Biol Chem 2006, 28 I (15): 10049-10055.

24. Aono R, Negishi T, Nakajima $\mathrm{H}$ : Cloning of organic solvent tolerance gene ost $A$ that determines $n$-hexane tolerance level in Escherichia coli. Appl Environ Microbiol 1994, 60( I 2):4624-4626.

25. White DG, Goldman JD, Demple B, Levy SB: Role of the acrAB locus in organic solvent tolerance mediated by expression of marA, soxS, or robA in Escherichia coli. J Bacteriol 1997, I79(19):6122-6126.

26. Tanaka T, Horii T, Shibayama K, Sato K, Ohsuka S, Arakawa Y, Yamaki K, Takagi K, Ohta M: RobA-induced multiple antibiotic resistance largely depends on the activation of the AcrAB efflux. Microbiol Immunol I997, 4 I(9):697-702.

27. Paulsen IT, Sliwinski MK, Saier MH Jr.: Microbial genome analyses: global comparisons of transport capabilities based on phylogenies, bioenergetics and substrate specificities. I Mol Biol 1998, 277(3):573-592.

28. Nishino K, Yamaguchi A: Analysis of a complete library of putative drug transporter genes in Escherichia coli. J Bacteriol 200 I, I 83(20):5803-58|2.

29. Koronakis V, Eswaran J, Hughes C: Structure and function of TolC: the bacterial exit duct for proteins and drugs. Annu Rev Biochem 2004, 73:467-489.

30. Piddock LJ: Clinically relevant chromosomally encoded multidrug resistance efflux pumps in bacteria. Clin Microbiol Rev 2006, I 9(2):382-402.

31. Sambrook J, Russell DW: Molecular cloning: a laboratory manual. 3rd edition. Cold Spring Harbor, NY, Cold Spring Harbor Press; 2001 .

32. Sikkema DJ, Brubaker RR: Resistance to pesticin, storage of iron, and invasion of HeLa cells by Yersiniae. Infect Immun 1987, 55(3):572-578.

33. Perry RD, Pendrak ML, Schuetze P: Identification and cloning of a hemin storage locus involved in the pigmentation phenotype of Yersinia pestis. J Bacteriol 1990, I 72(I 0):5929-5937.

34. Palma M, DeLuca D, Worgall S, Quadri LE: Transcriptome analysis of the response of Pseudomonas aeruginosa to hydrogen peroxide. J Bacteriol 2004, I 86(I):248-252.

35. Palma M, Worgall S, Quadri LE: Transcriptome analysis of the Pseudomonas aeruginosa response to iron. Arch Microbiol 2003, I 80(5):374-379.

36. Applied Biosystems. 1997. ABI PRISM 7700 Sequence Detection System, User Bulletin. 1997, 2: I-36.

37. Martin RG, Gillette WK, Rhee S, Rosner JL: Structural requirements for marbox function in transcriptional activation of mar/sox/rob regulon promoters in Escherichia coli: sequence, orientation and spatial relationship to the core promoter. Mol Microbiol 1999, 34(3):43 I-44I.

Publish with Bio Med Central and every scientist can read your work free of charge

"BioMed Central will be the most significant development for disseminating the results of biomedical research in our lifetime. "

Sir Paul Nurse, Cancer Research UK

Your research papers will be:

- available free of charge to the entire biomedical community

- peer reviewed and published immediately upon acceptance

- cited in PubMed and archived on PubMed Central

- yours - you keep the copyright
BioMedcentral 